\title{
Professional Training of Future Teachers for the Development of Speech Activity of Younger Schoolchildren
}

\author{
Aizhan Zh. Sapargaliyeva, ${ }^{1, \#,}$, Dinara Ye. Muratbekova ${ }^{1, \#}$, Ryszhamal K. Aralbaeva,", \\ Saule S. Zhakipbekova ${ }^{1, \#}$ and Aizhan S. Shynybekova ${ }^{1, \#}$ \\ ${ }^{1}$ Zhetysu State University named after I. Zhansugurov, Taldykorgan, Republic of Kazakhstan \\ ${ }^{2}$ Branch in Almaty Region, Academy of Public Administration under the President of the Republic of \\ Kazakhstan, Taldykorgan, Republic of Kazakhstan
}

\begin{abstract}
Objective: The purpose of the experiment was to determine the level of knowledge of future primary school teachers about dialogical speech in the lessons of a discipline "Self-knowledge" (content component), their ability to apply this knowledge in the process of developing the dialogical speech of primary school students with mental disorders (operational component) and the comprehensive using of knowledge about dialogical speech in the process of educational activity (motivational component).

Background: Professional training of future teachers of primary schools is currently one of the pressing problems in modern Kazakhstan. One such way is the introduction of a practice-oriented competence of the future primary school teacher. This involves the formation of professional competence of a primary school teacher, his ability to solve typical professional problems on the basis of acquired knowledge and experience.

Method: For determining the preparation of future primary school teachers for work on the development of dialogical speech of primary school students a pedagogical experiment consisting of ascertaining and formative stages was conducted.

Results: Scientific research on the methodology of speech development is aimed at finding methods, techniques, and forms of training that increase the effectiveness of such important components of the learning content as language and speech competence, which are part of the communicative competence of pupils. In scientific pedagogy and psychology, the purpose of education and training is to develop a child's personality. The development of personality is considered as a long process of acquiring the culture of the people. Speech culture is an integral part of the general culture, so speech development is the most important task of forming the personality of a preschool and primary school pupil. The key role in psychological development is played by external, oral, monological, dialogical, and written speech.
\end{abstract}

Conclusion: Interrelation of the investigated components can serve as a description of the level of preparedness of future primary school teachers.

Keywords: Speech activity, primary school pupils, practice-oriented competence, dialogical speech.

\section{INTRODUCTION}

Among various deviations in personality development, speech disorders are quite common, either acting as an independent primary defect or accompanying other forms of developmental pathology. Modern psychological studies indicate an increase in the number of children with deviations varied in their manifestations and severity regarding the formation and development of speech. However, the behavioural side in children with a speech impairment is a particular problem. The relevance of this study is conditioned by the insufficiently developed issues related to the features of teaching students with general speech underdevelopment and psychological disorders, ways to correct existing disorders, insufficient systematic methodological and practical material. Therefore, it is very important for future teachers to study issues related to children with special needs.

${ }^{*}$ Address correspondence to this author at the Zhetysu State University named after I. Zhansugurov, Taldykorgan, Republic of Kazakhstan; Tel: +7 (728) 222 21 94; E-mail: aizhan.sapargaliyeva@nuos.pro

\#These authors are equally contributed.
This subject is quite relevant since, in modern conditions, the problem of speech development in children of primary school age occupies a special place because a modern school requires a high level of mental and speech development from a child. Human speech is not only a means of communication but also a means of expressing thoughts. The more figurative and correct the speech, the more accurately the thought is expressed. The development of speech entails the development of mental operations, and, conversely, the development of thinking contributes to the development of speech. Speech mastery rebuilds the processes of perception, memory, thinking, improves all types of children's activities, and the "socialisation" of the child. Therefore, the teacher needs a special approach to teaching children with problems of the speech apparatus and psychological features.

The content of the teacher's professional activity includes diagnostic, correctional and developmental, organisational and methodological, advisory, 
educational, and preventive work. A significant part of children with speech impairments receives school education in state and municipal general educational institutions, provided that speech therapy is provided at preschool age or in primary grades in parallel with schooling. The possibilities of applying conventional approaches to teaching and diagnosing the behaviour and interpersonal relations of children with developmental disabilities are, to a certain extent, limited; therefore, the choice falls on projective methods. When interpreting these techniques, they proceed from the position that children in drawings express their $\mathrm{I}$, the features of which can be determined by the proposed system of criteria [1-4].

At different times, such authors as J. Piaget, A. R. Luria [5], L. S. Vygotsky [6], S. L. Rubinstein [7], and others dealt with the problems of speech development. They studied the mechanisms of speech, the main stages of its development, factors determining speech development, causes of speech disorders. An analysis of recent publications and research results show that the number of children with speech impairments is growing every year, and speech disorders themselves are taking on increasingly complex forms $[8,9]$. Quite often, a speech defect is immediately associated with several disorders of somatic and mental health. In other words, speech impairment is accompanied by deviations in the child's emotional-volitional sphere, mental and physical development. Thus, the question of the normal speech development of children and the prevention of speech disorders is of great social importance.

A huge number of factors influence the development of speech. This influence can be both positive and negative. As for the degree of influence of hereditary and environmental factors on the development of speech, we can confidently state the following. Congenital abilities, a strong desire to communicate with others, and the richness of the language and social environment combine to help children learn the functions and patterns of their native language $[10,11]$.

In recent years, there has been an increase in the number of children with speech development disorders [12]. According to some domestic sources, the prevalence of speech development disorders is up to $25 \%$ among school-age children [13]. Moreover, pronounced speech disorders require differential diagnosis not only with mental retardation but also in a number of cases with intellectual disability. Speech development disorders are at the junction of many physiological features of the body. Speech function is key to the development of the child's thinking and intelligence in general; therefore, a violation of the formation of speech inevitably entails a lag in the development of thinking, a violation of communication and socialisation, the occurrence of behavioural disorders, and school failure [14]. Violations of speech development can be observed with a wide range of diseases found in general paediatric practice.

One of the priority tasks of higher education is the preparation of a qualitatively new, flexible, competitive, competent, highly qualified teacher with broad fundamental knowledge, who is able to independently and creatively solve professional problems, able to quickly adapt to the constantly changing requirements of the labor market, able to effectively fulfill professional activity and be responsible for its results [15-17].

The problem of training teachers for primary schools is currently associated with searching for ways to bring the university's educational process to the realities of the primary schools for children with mental and speech disorders. One such way is the introduction of a practice-oriented competence of the future primary school teacher. This implies the formation of the professional competence of an elementary school teacher, his ability to solve typical professional problems on the basis of acquired knowledge and experience [18].

The purpose of the study is to substantiate the theoretical and methodological foundations and to develop methodological foundations for the future teacher's training for the development of dialogical speech of younger students with mental disorders.

\section{MATERIALS AND METHODS}

In the study, we used the following general scientific methods: pedagogical observation, analysis, synthesis, systematization and generalization, methods of the pedagogical experiment: ascertaining, formative, questionnaires, conversations, methods of mathematical statistics. In order to determine the initial level of readiness of future elementary school teachers to work on the development of dialogical speech of elementary school students with mental disorders, a stating experiment was conducted. The willingness of future teachers includes three components of educational activity: substantive, operational, and motivational. The relationship between these 
components can serve as a characteristic of the level of readiness. Tasks of the ascertaining experiment:

1. To identify the level of students' knowledge about dialogical speech and their ability to apply this knowledge in the process of developing the dialogical speech of younger students.

2. Determine the levels of formation: the ability to analyse a fragment of the lesson "Selfknowledge" with elements of discussion; the ability to prepare a fragment of the lesson "Selfknowledge" with elements of the discussion.

In order to determine the level of knowledge of future teachers about dialogic speech (substantive component), their ability to apply this knowledge in the process of developing the dialogical speech of elementary school students (operational component), and awareness of the use of knowledge about dialogical speech in the process of an educational activity (motivational component), a survey was conducted of students of the 3rd year of the educational program - "Pedagogy and Methods of Primary Education" (PMPE) on the following issues:

1. What is called a dialogue? Indicate the features of its construction.

2. What are the types of dialogue? Which of them do you use in the lessons of "Self-knowledge" and for what purpose?

3. Choose the works you would use to conduct a conversation-discussion in the classroom reading lesson, justify your choice: $M$. Abylkasymov "Native land"; V. Oseeva "What is easier?"; Japanese fairy tale "Six rules for statues".

In order to determine the level of knowledge of future teachers of elementary school about dialogical speech in the lessons of "Self-knowledge" (substantive component), their ability to apply this knowledge in the process of developing the development of dialogical speech of younger students with mental disorders (operational component) and the awareness of the use of knowledge about dialogic speech in the learning process (motivational component) [19].

The training experiment was developed on the basis of the content of the process of preparing future primary school teachers in the subject of "Selfknowledge". A course was developed on the university component 2 credits (60 hours) - 10 lectures, 10 practical exercises, 20 (IWS), 20 (IWS).

The formative experiment took place in 3 stages:

1. Formation of theoretical knowledge about dialogic speech and dialogue learning.

2. The formation of theoretical knowledge and skills in practice.

3. Application of theoretical knowledge and skills in practical activities.

A feature of the experimental program is that the sequence of work is determined, taking into account the links between knowledge of dialogic speech and communicative-speech skills.

An analysis of the psychological and pedagogical literature showed that in elementary school, one of the forms of educational dialogue is possible - a heuristic conversation with elements of discussion; therefore, when teaching future teachers, we focused on this form of educational dialogue. The goal of each lesson of the university component was to develop the ability of future teachers to organize and conduct an educational dialogue. A means of achieving this goal was the formation of the ability to prepare and conduct a lesson (or a fragment of a lesson) "Self-knowledge" with elements of the discussion. The skill was formed on the basis of educational and methodological tasks, as well as modelling of real pedagogical activity at the lessons "Self-knowledge". The teacher should know: the theoretical foundations of the psychology of the development of people with speech impairments; causes, mechanisms, and types of speech disorders; features of mental development in various speech pathology; methods for studying the psyche of people with speech impairments; the specifics of diagnostic and correctional work with this category of children; features of an individual approach to children with various speech disorders.

The survey was attended by 100 future teachers of the 3rd year of "PMPE". The questionnaire was offered to students in a practical lesson on the topic: "Tasks, methods of development of speech activity." Thus, students answered the questionnaire without preliminary preparation, relying on personal experience and work experience at school. The first two questions of the questionnaire are aimed at revealing knowledge about dialogic speech. The second question involved not only identifying a certain circle of knowledge but 
also elucidating the motive of students' activities as a teacher. The choice of the works presented in the third question is due to the fact that it includes works of two genres (fairy tale, story) of different subjects. In each of the aforementioned works, one can single out the problem, on the basis of which the conversation with the elements of discussion is based. For example, according to the Japanese fairy tale "Six Rules for Statues" - true and false kindness; according to the story of M. Abylkasymov "Native land", V. Oseev "What is easier?" - the nature of human actions. Therefore, the justification for the choice of works is so important. Therefore, justifications for choosing works for discussion are so important.

The obtained questionnaire data were taken into account by us in experimental training. When conducting a training experiment, it is necessary to inform students of knowledge from the field of linguistics (about the nature and features of dialogue, to give an idea of the educational dialogue, its structure, and functions), and from the field of speech (types of communication activity, discussion speech, motive for educational activity, pedagogical dialogue, pedagogical communication, teaching and speech situation, text topic). There is every reason to believe that for the effective work of the teacher, this knowledge is necessary. During the experiment, the readiness of students to work on the development of dialogical speech of younger students with mental disorders was established. Each level included three components of educational activity: substantive, operational, motivational. The relationship between these components can serve as a characteristic of the level of readiness.

The content component of the educational activities of future teachers includes the following knowledge:

1) from the field of linguistics: the definition of dialogue, types of dialogue (conversation, debate, dispute, discussion), the features of building a dialogue (replica, question-answer form, the role of interlocutors);

2) from the field of methodology: techniques for analysing a work of art, relevant methods and techniques for working with a book in the lessons "Self-knowledge";

3) from the field of pedagogy: the essence of cognitive activity, a problematic issue, a problematic situation, a lesson.
Also, from 2006 to the 2009 academic year, under our supervision were 256 primary schoolchildren grades $1-4$ (boys 158 , girls 98 ), average age $7.5 \pm 1.1$ years, students in secondary school No. 12 of the city of Taldykorgan, with this revealed 109 (42.6\%) students (boys 74, girls 35 ) with speech disorders; of them with general speech underdevelopment (GSU) $28(10.9 \%)$, with phonetic-phonemic underdevelopment (PPU) -49 (19.2\%), and with phonetic speech impairment (PSI) - 32 (12.5\%). The remaining 147 (boys 82, girls 65) made up the control group.

\section{RESULTS}

For students with a violation of the speech apparatus and psychological features, a special training program is required. In special (correctional) institutions, the curriculum has been modified, systematic speech therapy assistance has been provided, manuals and textbooks developed in accordance with the capabilities of children with speech impairments are used. However, at present, the issue of integrating children even with severe speech disorders into the environment of peers who have no limited health abilities is widely discussed. The task of socialisation and integration of children with speech impairments is feasible, provided that their educational needs are taken into consideration.

The special educational needs of children with severe speech impairment include the following:

- $\quad$ the need for a coincidence of the beginning of correctional developmental training with the moment of identifying and determining a violation in the development of a child's speech;

- improvement of the development of sensory, motor, and higher mental functions interconnected with speech;

elimination of neurological and psychopathological disorders, often accompanying speech disorders of a central organic origin;

- constant stimulation of speech and cognitive activity of the child, stimulation of interest in oneself, surrounding objects, and the social world;

- training in various forms of communication (verbal and non-verbal).

It should be noted that, in contrast to the United States and European countries, in Kazakhstan, there is 
a decline in psychiatrists' interest in speech disorders in children. Some patients with sensorimotor alalia syndrome are diagnosed as part of an autism spectrum disorder since the similarity of individual symptoms can often be observed [20]. Therefore, future teachers need to have the training to work with such children. The relevance of identifying and realising by teachers of the special educational needs of young schoolchildren with speech impairments is largely conditioned by the fact that the contingent of children has recently changed, both in terms of speech development and in terms of preparedness for learning. There are two main tendencies in the change in the contingent of children with speech disorders. One tendency is to increase the number of children with minimal manifestations of speech disorders by school age, which is associated with the timely provision of speech therapy and the use of modern pedagogical technologies. Another one indicates that the number of children with a complex structure of speech disorders, with severe speech disorders of an organic nature, combined with psychophysical development disorders [21] has also increased.

Table 1 presents the results of the level of knowledge of 100 third-year students about dialogue with schoolchildren with speech and psychological disorders. Results are presented in percentage correlation.

The majority of future teachers, answering the first question, correctly define the dialogue as a conversation between two persons $(27.5 \%)$; two or more persons $(25.5 \%)$. Of the respondents, $9 \%$ rightly believe that dialogue is a way of communication between two or more people. "Dialogue is a way of communication between people, which allows you to both express your point of view and listen to the interlocutor; makes it possible to understand the opponent's response" (K. Aruzhan). "A dialogue is a conversation of two or more people in which people exchange opinions, experiences, desires. Both parties should participate in the dialogue" - R. Yerkezhan. These answers correspond to the definition of dialogue adopted in linguistics.

$38 \%$ were unable to give a precise definition of the dialogue: "Dialogue is one of the forms of oral speech" - 5.5\%; "This is information transfer" - $5.5 \%$; "Statement of one's point of view" $-6.0 \%$; they call the type of dialogue instead of determining - 10.0\%; "Dialogue is a conversation between two people" $8.5 \%$; "Dispute" -2.5 . The above answers do not quite correspond to the accepted definitions. Calling the features of building a dialogue, students indicate the main ones: alternate replicas exchange - 36\%; a question-answer form of dialogue - $43 \%$; the active role of the interlocutor (the ability to hear, listen and speak) $-9 \%$. As can be seen from Table 1, not all types of dialogue are familiar to students. They call one of the types of dialogue, or discussion, or conversation, or argument. Speech disorders can cause specific deviations from other higher mental functions (attention, memory, verbal thinking), adversely affect the emotional-volitional and personal sphere, which generally complicates the picture of the child's speech disturbance. The educational activity of children with severe speech impairments is described by a slower rate of perception of educational information, difficulties in establishing associative connections between visual, auditory, and speech-motor analysers; difficulties in organising voluntary activities, a low level of selfcontrol, and low working capacity. All this can lead to a decrease in children's motivation for learning and failure to achieve vital goals.

The problem of correction and rehabilitation of children with speech disorders is relevant due to difficulties in learning and adaptation to school conditions [22]. Overcoming these difficulties should be facilitated by scientifically based, adequate corrective measures based on comprehensive diagnostics results

Table 1: The Level of Students' Knowledge about the Dialogue with Schoolchildren with Mental and Speech Disorders (in \%)

\begin{tabular}{|c|c|c|c|c|c|}
\hline No. & Dialogue Knowledge & Correct answer & Incomplete answer & No answer & Total \% \\
\hline 1 & Dialogue definition & 62 & 38 & & 100 \\
\hline 2 & $\begin{array}{l}\text { Features of building a dialogue: } \\
\begin{array}{r}\text { - exchange of remarks; } \\
\text { - question and answer form } \\
\text { - the active role of the interlocutor }\end{array}\end{array}$ & $\begin{array}{c}36 \\
43 \\
9\end{array}$ & $\begin{array}{c}49 \\
- \\
33\end{array}$ & $\begin{array}{l}15 \\
57 \\
58\end{array}$ & $\begin{array}{l}100 \\
100 \\
100\end{array}$ \\
\hline 3 & Types of dialogue & - & 41 & 59 & 100 \\
\hline
\end{tabular}


aimed at identifying individual psychological features of children, which is what future educators are teaching [22]. In the course of teaching practice, students conducted a study among 256 primary school students of grades 1-4. The child's speech development level largely determines the success of schooling; however, a significant part of children aged 6-7 years (about $60 \%$ ) have speech development disorders. Some of them can be overcome in the conditions of training in special schools for children with severe speech impairments; others can be eliminated in the conditions of a comprehensive school at speech therapy centers. The sooner their correction begins, the higher the effectiveness of eliminating speech deficiencies, not complicated by secondary consequences, as well as the accompanying pedagogical neglect. Children with general speech underdevelopment (GSU) belong to the category of students who need speech therapy in the first place [23]; this group of students requires special attention of a speech therapist, as it is very heterogeneous both in severity and in manifestations of speech disorders (Table 2).

During the conversation, $84.7 \%$ of children with GSU gave monosyllabic answers, which is typical for a violation of the dynamic organisation of activities; the rest $(15.3 \%)$ talked in more detail about family and friends, but at the same time included insignificant details in the descriptions, digressed to side associations that were not directly related to the issue, which is noted when there is an optical-spatial insufficiency in the organisation of mental activity. In the process of preparing for the training of such students, the future teacher needs to consider all the details of the lesson. The question of the questionnaire caused the students' greatest difficulty, in answer to which it was necessary to indicate the purpose of using different types of dialogue in the lesson "Selfknowledge". $75 \%$ of all respondents could not answer. $25 \%$ named the following goals: to reveal the attitude of children to the actions of heroes; develop speech, communication skills; create an opportunity for the actions of heroes; develop speech, communication skills; $75 \%$ of all respondents could not answer. $25 \%$ named the following goals: to reveal the attitude of children to the actions of heroes; develop speech, communication skills; create an opportunity for the actions of heroes; develop speech, communication skills. The most interesting, in our opinion, is the opinion of A. Sholpan: "With the help of dialogue (debate, discussion) in the lesson, the teacher teaches children to listen, speak, accept and understand defeat." The inability of the majority of students $(75 \%)$ to determine the motive for learning activity is explained not by the possession of the concept of "dialogue", lack of knowledge and skills in the subject of "Self-knowledge", as well as poor speech training. The question in the questionnaire set out to find out the initial level of awareness of choosing work for a lesson with elements of the discussion. Students were offered the following task: "What works would you use to conduct a discussion - discussion in the lesson "Selfknowledge"? Justify your choice:

\section{a) M. Abylkasymov "Native land"; \\ b) V. Oseeva "What is easier?"; \\ c) Japanese fairy tale "Six rules for statues".}

Offer your version of the artwork for discussion". The answers were distributed as follows: $20 \%-$ justified the choice of the Japanese fairy tale "Six rules for statues"; $18 \%$ - works of V. Oseev "What is easier?"; $15 \%$ - M. Abylkasymov "Native Land". Almost half of the respondents $(47 \%)$ were unable to substantiate their choice. This is due to insufficient knowledge of the texts (books were not offered, restored the contents from memory), as well as poor literary preparation (inability to analyse works of art). A large number of students $(63 \%)$ preferred the Japanese fairy tale. Only $20 \%$ explained their choice (a fairy tale is a close and understandable genre to

Table 2: The Incidence of Speech Disorders in Primary School Students

\begin{tabular}{|c|c|c|c|c|c|c|}
\hline $\begin{array}{c}\text { Academic } \\
\text { year }\end{array}$ & $\begin{array}{c}\text { The total number of } \\
\text { children examined }\end{array}$ & Control group & $\begin{array}{c}\text { Identified with } \\
\text { speech impairment }\end{array}$ & GSU & PPU \\
\hline \hline $2015 / 16$ & 82 & $48(58.5)$ & $34(41.5)$ & $11(13.4)$ & $12(14.7)$ & $11(13.4)$ \\
\hline $2016 / 17$ & 86 & $50(58.1)$ & $36(41.8)$ & $8(9.3)$ & $18(20.9)$ & $10(11.6)$ \\
\hline $2017 / 18$ & 88 & $49(55.6)$ & $39(44.2)$ & $9(10.2)$ & $19(21.5)$ & $11(12.5)$ \\
\hline Total & 256 & $147(57.4)$ & $109(42.6)$ & $28(10.9)$ & $49(19.2)$ & $32(12.5)$ \\
\hline
\end{tabular}

Note. In parentheses are percentages. GSU - children with general speech underdevelopment; PPU - children with phonetic-phonemic underdevelopment of speech; PSI - phonetic underdevelopment of speech. 
children, by the presence of a problem). "If there is a problem, then a dispute may arise, discussion - B. Aigerim, $23 \%$ of respondents, chose the work of $\mathrm{V}$. Oseev "What is easier?", As a justification, many students say that children with mental disorders can distinguish between truth and falsehood, which will be instructive. Students associate the choice of $M$. Abylkasymov's short story "Native Land" with a close and familiar topic for younger schoolchildren - peers' actions, how they show love for their native land (16\%).

One of the tasks included the ability to independently choose work and give a rationale for the choice. They call their version $77 \%$ and determine it correctly. The choice is justified by interesting, understandable, and accessible themes of fiction, the possible creation of a problematic situation. One can agree with this approach, as this contributes to the named criterion for the selection of works and program requirements. Thus, students have little theoretical knowledge of dialogic speech. The greatest difficulties are caused by the determination of structural features and types of dialogue. Students cannot indicate the purpose of using dialogue in the lesson "Selfknowledge". This is caused not only by the lack of theoretical knowledge but also by a lack of understanding of the need for their use in the educational process. Students find it difficult to choose a work of art for the lesson "Self-knowledge" with elements of discussion, which suggests a lack of theoretical speech training of students, inability to apply knowledge in practice. The obtained questionnaire data were taken into account by us in experimental training. As a result of the ascertaining experiment, we were able to identify four levels of readiness of future teachers to work on the development of dialogical speech of younger students: zero, low, medium, and above average (Table $\mathbf{3}$ ).

The zero levels is characterized by the lack of formation of the substantive and operational components. Students cannot organize and prepare a conversation - a discussion for the lesson "Selfknowledge", because they do not have theoretical knowledge of dialogic speech, some pedagogical, and literary knowledge. Also, students at the zero level do not know how to use individual knowledge in educational activities (for example, choose a work of art for the lesson "Self-knowledge" with elements of discussion); they cannot analyse a lesson fragment. The motivational component is characterized by the fact that the student is not aware of the purpose of using dialogue in the educational process and, therefore, does not feel the need to use it in the lesson.

Future teachers, who are at a low level, are partially aware of the motives for using dialogue in the lesson (for example, only one motive is indicated in the questionnaire, for example: "the most rational choice for solving the problem", A. Anar). Many people understand that the use of dialogue helps to build the learning process at a higher level, but they cannot precisely determine the purpose of the educational dialogue.

The average level is characterized by the incomplete formation of the ability to prepare a conversation - a discussion on the subject of "Selfknowledge". The operational component at this stage is characterized by the following features: future educators occasionally make individual mistakes in choosing a work; have difficulty determining the purpose of the lesson; admit inaccuracies in the formulation of problematic issues; do not think through to the end of the conversation. Future teachers, who are at the middle level, recognize and formulate the motives of educational activity, indicate one or two motives (for example, Sh. Vika: "I use the dialogue in the lesson "Self-knowledge" to collide different points of view, resolve conflict situations, and controversial issues that arise during the discussion of the work").

The level above the average is determined by the complete awareness of students about dialogical speech: a fairly clear definition of dialogue; its main structural features are indicated; some conditions for the emergence of dialogue in the lesson, types of educational dialogue: teacher-class, internal dialogue (with oneself) are named. For example: "Dialogue is a two-way communication process (both a teacher and a student can pose a problem)", - N. Bota.

The operational component of this level is characterized by the following skills:

Table 3: Levels of Readiness of Students to Work on the Development of Dialogical Speech of Primary School Students (in \%)

\begin{tabular}{|c|c|c|c|}
\hline Level zero & Low level & Average level & Above-average level \\
\hline \hline 7 & 37 & 45 & 11 \\
\hline
\end{tabular}


- $\quad$ the ability to use individual knowledge of dialogic speech in educational activities;

- $\quad$ the ability to justify the choice of a work of art;

- identify and shape the topic, purpose of the conversation-discussion;

- $\quad$ the ability to formulate a problematic issue and create a problematic situation;

- $\quad$ think over the course of the conversation.

Students at this level choose not one but two works of art for work, combining them with one theme (for example, K. Kaysenov "Young Heroes" and S. Kumisbaev "Three Batyrs", discussion topic discussions - What qualities should possess the defender of the homeland?). The effectiveness of experimental training at each stage was largely determined by the correctness of the choice of the text of the work of art. One of the main tasks of the lessons "Self-knowledge" is "to teach children to think about a book."

The next criterion is the variety of genre material. A characteristic feature of stories, fairy tales, poems is a dialogical form of presentation of the material, which greatly increases the interest of children in works and contributes to the development of oral speech. Humour and laughter are of great educational and developmental importance. Thus, we have identified the following criteria for selecting texts of fiction for the lesson "Self-knowledge" with elements of discussion:

1. Consideration of program requirements (taking into account age-related characteristics; availability of educational material by content, volume; interest in a given topic).

2. Correspondence of the didactic purpose of the conversation-discussion.

3. The presence of problems.

4. Artistic originality (theme, storyline, belonging to a certain genre).

The formation of the ability to develop a dialogical discussion of the problem. The substantive side of this skill is knowledge of the methods and techniques of dialogue learning. The operational side consists of the following skills: Consciously choose methods and techniques of dialogue learning; the ability to apply them.
Much attention was paid to teaching students the conscious choice of dialogic methods and techniques. (For example, the purpose of the work: to identify a problematic issue; to justify the choice of methods and techniques used in the lesson fragment; or to justify the possibility/impossibility of any dialogue in the lesson; indicate techniques that facilitate the organization and provide educational dialogue). An analysis of the data showed that educators consciously choose a method and techniques that contribute to the formation of the ability to develop a dialogical discussion of the problem. They sufficiently learned to correlate the types of work with the theme and type of the lesson "Selfknowledge". This was achieved on the basis of attracting knowledge about educational dialogue, about a lesson with elements of discussion, about methods and techniques of dialogical learning. At the 3rd stage, the educational task was: improving professional, communicative knowledge and skills at a new creative level. Basic skills: The ability to formulate a problem; the ability to develop a dialogue discussion of the problem.

Improvement of these skills was carried out in more difficult conditions (independent selection of work for discussion, methodological substantiation of teaching methods, an independent compilation of a lesson in the lesson "Self-knowledge" with elements of discussion, its conduct, and analysis of learning outcomes). According to this situation, students were given the task: to independently prepare and conduct a lesson on "Self-knowledge" with elements of the discussion. An experimenter with a group of students attended such classes in primary school. Thus, the analysis of the lesson "Self-knowledge" conducted by the future teacher provided the opportunity for students to clarify the structure of the lesson "Self-knowledge" with elements of discussion, its focus on each stage, methods of dialogue learning, the specifics of problematic issues that allow students to increase their mental activity.

In the analysis of the lesson, the subject of consideration was such professional, communicative skills of the teacher as the ability to formulate a problem and the ability to achieve dialogic in the lesson. In this regard, students analysed the following methods and techniques of dialogue learning used in the educational process: a conversation with the elements of discussion, different types of questions, improvisation, "teasing interlocutor". In the lesson, teachers skilfully demonstrated dialogues: teacher- 
Table 4: The Levels of Readiness of Students to Work on the Development of Dialogical Speech of Primary School Students (in \%)

\begin{tabular}{|c|c|c|c|c|c|c|c|}
\hline \multicolumn{2}{|c|}{ Zero level } & \multicolumn{2}{c|}{ Low level } & \multicolumn{2}{c|}{ Average level } & \multicolumn{2}{c|}{ Level above the average } \\
\hline $\begin{array}{c}\text { Before } \\
\text { training }\end{array}$ & $\begin{array}{c}\text { After } \\
\text { training }\end{array}$ & $\begin{array}{c}\text { Before } \\
\text { training }\end{array}$ & $\begin{array}{c}\text { After } \\
\text { training }\end{array}$ & $\begin{array}{c}\text { Before } \\
\text { training }\end{array}$ & $\begin{array}{c}\text { After } \\
\text { training }\end{array}$ & $\begin{array}{c}\text { Before } \\
\text { training }\end{array}$ & $\begin{array}{c}\text { After } \\
\text { training }\end{array}$ \\
\hline \hline 7 & - & 37 & 8 & 45 & 52 & 11 \\
\hline
\end{tabular}

student, teacher-class; some fragments of dialogues: student-teacher, student-student.

Thus, as can be seen from Table 4, the level of readiness of future teachers to work on the development of dialogical speech of younger students in experimental groups is much higher than in groups before training. This is evidenced by a significant difference in the number of the fourth level ("above average"); in comparison with the stating experiment.

\section{DISCUSSION}

Currently, the problem of the development of speech in children is attracting the attention of many psychologists. Speech is a psychic function due to which people get ample opportunities to communicate with each other. Based on speech and words - the semantic unit of speech - such mental processes as perception, imagination, and memory are formed and developed. In the school period, favourable conditions are created for the development of speech, the foundation is laid for written forms of speech - reading and writing, and the subsequent speech and language development of the child. In his works, psychologist A.N. Leontyev considered language and speech as private use of the language from the standpoint of specific human activities. His works raise the issues of communication as an activity, the social meaning of communication, the correctness, and legitimacy of the use of such a term as "speech activity" in schools. According to A.N. Leontiev: "On the one hand, language is a product of specific, adequate activity; it is where this activity objectifies itself. On the other hand, it is the objective basis of the speech activity of the individual" [24].

Thus, L.S. Vygotsky showed that word usage errors are associated with patterns of development of children's thinking, patterns of analysis, and generalization, when generalizations by random emotionally significant, non-essential signs become the meaning of certain words for children and do not coincide with the socially fixed meaning of the words.
Therefore, relying on the work of L.S. Vygotsky, it can be noted that the development of the meaning of the word and the elimination of errors of use should be associated with the development of conceptual thinking, with the development of the concept [6]. With the development of thinking, knowledge is rearranged, and they take the form of concepts, and the word in the child's consciousness is associated with the concept, acquires a socially fixed meaning. Based on the previous, for the theory of vocabulary work, research on the consistency of knowledge among younger schoolchildren is of great importance, since the knowledge system provides a transition to the development of concepts, the development of the foundations of conceptual thinking in younger students based on the enrichment of visual-effective to visualfigurative thinking. [25-28]. However, studies of recent decades have shown that concepts are mastered by children at the senior preschool and primary school age if their content can be presented visually. This position is confirmed in several studies in the field of natural science and the knowledge of the world.

S.L. Rubinstein noted that speech is a specific and integral part of human behaviour at large, as a complex system of deeds, actions, movements. Speech behaviour is a form of a person's social being (or its functioning in society). More precisely, speech is a form of consciousness for another, serving as a means of communicating with it, and a form of generalised reflection of reality, or a form of thinking. Therefore, it is necessary to use a philosophical approach during teaching [7]. Psychologist V. Humboldt notes that speech is a means of communication between people and a form of human thinking [11]. Therefore, her theorem is slightly similar to this study since it implies a dialogue. R.E. Levina believes that "speech is not an innate ability of a person, it is formed gradually, along with the development of the child", and psychologist E.I. Tikheeva notes: "Speech is a combination of pronounced or perceived sounds that have the same sense and the same meaning as the corresponding system of written signs" [29]. In the current study, the authors believe that a creative approach is necessary for teaching children with speech and psychological 
disorders. Connecting speech with the process of creativity is the leading line in the formation of the psyche, since speech is not given to the child in a finished form, but is contrived, invented by it in the process of communicating with adults.

In this paper, the authors believe that in the learning process, it is necessary to develop external, oral, monological, dialogical, and written speech. External speech is a system of sound signals used by a person, written signs and symbols for transmitting information, the process of materialisation of thought. Oral speech is a form of speech activity, including understanding sounding speech and the implementation of speech utterances in a sound form (speaking). Monologue speech is a large active, or arbitrary type of speech. In other words, to carry out a monologue speech, the speaker usually must have some kind of content and be capable of building their own statement or sequence of statements based on this content. Finally, monologue speech is a very organised kind of speech. Dialogic speech - this speech is more situational, i.e., related to the environment in which the conversation takes place and contextual, i.e., each statement is largely conditioned upon the previous one. Written speech is a kind of monological speech. Writing implies a lack of feedback from the interlocutor.

Later, based on a generalisation of many studies, A.N. Leontiev attempted to build a theory of the development of a child at school age, proceeding from the fact that "the change in the place occupied by the child in the system of social relations is the first thing that should be noted upon trying to solve the issue of the driving forces of the development of its psyche [10]. However, this place alone does not, of course, determine the development; it only describes the present, already achieved level. What directly determines the development of the child's psyche is its life itself, the development of the real processes of this life, in other words, the development of the child's activities, both external and internal" [24]. From this standpoint, school-age can be understood as a period of intensive assimilation of an example of adults (norms and rules of behaviour that act as a generalisation of people's relations) and the formation of mechanisms of personal behaviour, i.e., mechanisms for subordinating one's attitude to things and other people ideally given to samples learned from adults. During this period, types of activity also arise that differ not only in content but also in the form of an adult's presence in a particular child's activity. In her theory of the development of thinking of a schoolchild, L.F.
Obukhova writes that in Russian psychology, there has been a change in ideas about the mental development of a preschooler due to the separation in an action of two parts: orientational and executive [19]. Research by A.V. Zaporozhets, D.B. Elkonina, P.Ya. Halperin allowed presenting mental development as a process of separating the orientational part of the action from the action itself and enriching the orientational part of the action due to the formation of methods and means of orientation. At this age, orientation itself is carried out at different levels: material (or practically effective), perceptual (based on visual objects), and mental (without reliance on visual objects, in terms of presentation). Therefore, when referring to the development of perception usually implies the development of methods and means of orientation.

At the same time, the formation of systemic knowledge, revealing in its diversity and completeness the essential features of objects of cognition and their diverse relationships, allows students to reveal the variety of aspects of reality and, on this basis, introduce a variety of words that denote the known sides, features of objects and phenomena of the world. Therefore, systemic knowledge its formation will allow to most successfully solve the problems of vocabulary work in elementary school, to optimize the development of speech of younger students. For elementary school children, the need for utterances, the presence of the content of the utterance, and the availability of language means for the child are important.

\section{CONCLUSIONS}

The training of future teachers in pedagogical specialties is of particular importance. During the ascertaining experiment, the levels of readiness of future teachers to work on the development of dialogic speech in the lesson "Self-knowledge" were determined. The obtained results of the ascertaining experiment confirmed the need to create a methodological system for working on the development of dialogical speech in younger students with speech and mental disorders. An analysis of the results of the formative experiment allows us to state that the psychological and pedagogical work carried out to prepare future primary school teachers to work on the development of dialogical speech in elementary school students turned out to be effective.

1. As a result of the formative experiment, an elective course of the university component was 
developed "Formation of future elementary school teachers to work on the development of dialogical speech of children":

- $\quad$ selected psychological and pedagogical material necessary for the formation of professional, communicative and speech skills;

- $\quad$ EMCD and syllabus have been developed, which contribute to the targeted preparation of future teachers to work on the development of dialogical speech of younger students;

2. As a result of the formative experiment, it was found that the effectiveness of preparing future teachers for work on the development of dialogical speech of younger schoolchildren increases if the system of education implements relationships between the content, motivational and operational components.

3. The pedagogical conditions that contribute to the preparation of future teachers for creative work with children in the lessons "Self-knowledge" are highlighted.

4. Analysis of the obtained data from the formative experiment allows us to judge the increased level of preparation of future teachers for work on the development of dialogical speech of younger students.

Speech is an important mental function of a person, which has its own functions, types, properties, and criteria. School-age is a period of rapid physical and mental development of the child, the initial formation of physical and mental qualities necessary for a person throughout their subsequent life. A feature of this period, which distinguishes it from other subsequent stages of development, is that it provides precisely the general development, which will facilitate the further acquisition of any special knowledge and skills, the assimilation of various types of activities. Thus, disorders of speech development in children can be a symptom of a wide variety of conditions.

\section{ACKNOWLEDGEMENT}

None.

\section{REFERENCES}

[1] Shcherba LV. Language system and speech activity. Leningrad: Nauka, 1974.
[2]

Sheryazdanova HT. Realities and prospects for the training of specialist psychologists in higher education. Almaty: Kazakh University, 2019.

[3] Mukazhanova RA, Omarova GA, Saparbayev AB. Selfknowledge. Almaty: NSPERC "Bobek" 2016.

[4] Makarova VN. Effectively targeted and meaningful components of teacher training for the speech and linguistic development of speech of preschool children. Uchenye Zapiski Oryol State University. Series of Humanities and Social Sciences 2016; 2(8): 239-246.

[5] Luria A.R., Yudovich, F.A. Speech and development of mental processes of the child. Moscow: Pedagogika, 2008.

[6] Vygotsky LS. An experimental study of the development of concepts. Moscow: Pedagogika, 1982.

[7] Rubinstein SL. Fundamentals of General Psychology. Moscow: State Study-Pedagogical Publishing House of the Ministry of Education of Russian Soviet Federative Socialist Republic, 1946.

[8] Vetrova V.V., Smirnova E.O. The child learns to speak. Moscow: Znaniye, 2008

[9] Volkov, B.S., Volkova, N.V. Psychology of communication in childhood. Moscow: Pedagogika, 2013.

[10] Sapargalieva AZh, Muratbekova DE. The development of speech activity in children of primary school age. Reports of the Kazakh Academy of Education 2019; 3: 152-161.

[11] Humboldt V. Language and philosophy of culture. Moscow: Progress, 1985.

[12] Razenkova, YuA, Teplyuk SN, Vyrodova IA. The development of speech in young children. Moscow: AyrisPress, 2007.

[13] Gerasimova, AS. Unique speech development guide. Moscow: Ayris-Press, 2011.

[14] Lisina MI. Communication and speech: The development of speech in children in communication with adults. Moscow: Pedagogika, 2010.

[15] Platonova NM, Platonov MYu. Modern trends in the development of higher education. Uchenye Zapiski SPbGIPSR 2014; 1(21): 81-86.

[16] Sapargaliyeva A, Aralbayeva R, Sheriyazdanova H, Rybekov $\mathrm{K}$. Training of specialists of helping professions in the Republic of Kazakhstan. Mediterranean Journal of Social Sciences Rome-Italy 2015; 6(2): 111-114. https://doi.org/10.5901/mjss.2015.v6n2s4p111

[17] Sapargaliyeva A. Improving of the professional training of a pedagogical psychologist as a specialist of helping professions: theory and practice. Taldykorgan: Altyn baspa, 2019.

[18] Markova AK. Formation of motivation for learning at school age 2010. Available at: http://www.studmed.ru/markova-akformirovanie-motivacii-ucheniya-v-shkolnomvozraste_dbdd3e70456.html (04.23.2020).

[19] Obukhova LF. Psychology. Moscow: Politizdat, 2007.

[20] Lyamina GM. The development of speech of a young child. Moscow: Ayris-Press, 2009.

[21] Vinarskaya EN. Early speech development of the child and problems of defectology. Moscow: Terevinf, 2011.

[22] Alekseeva MM, Yashina VI. Methods of development of speech and teaching the mother tongue of preschoolers. Moscow: Feniks, 2009.

[23] Vetrova VV, Smirnova EO. The child learns to speak. Moscow: Znaniye, 2008

[24] Leontiev AA. Language, Speech, Speech Activity. Moscow: Pedagogika, 2007.

[25] Mukhina V.S. Six year old child at school. Moscow: Akademiya, 2009. 
[26] Aralbaeva RK. Preschool Pedagogy. Taldykorgan: MES RK, ZhSU, "Zhetysu Universit baspasy", 2011.

[27] Gogoberidze AG. (Ed.). Preschool pedagogy with the basics of methods of education and training. Third Generation Standard. St. Petersburg: Piter, 2013.
[28] Krulekht MV. The problem of the holistic development of a preschool child as a subject of labor. St. Petersburg: Accident, 1995.

[29] Tikheeva El. Children speech development. Moscow: Smysl, 2008.

Received on 25-07-2020

Accepted on $20-08-2020$

Published on 14-09-2020

DOI: https://doi.org/10.6000/2292-2598.2020.08.03.12

(C) 2020 Sapargaliyeva et al.; Licensee Lifescience Global.

This is an open access article licensed under the terms of the Creative Commons Attribution Non-Commercial License (http://creativecommons.org/licenses/by-nc/3.0/) which permits unrestricted, non-commercial use, distribution and reproduction in any medium, provided the work is properly cited. 